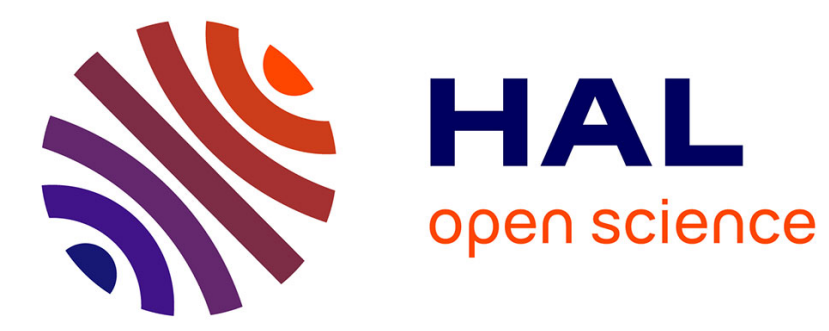

\title{
Effect of Magnetic and Material Structure on Epitaxial Garnet Coercivity
}

\author{
G. Vértesy
}

\section{To cite this version:}

G. Vértesy. Effect of Magnetic and Material Structure on Epitaxial Garnet Coercivity. Journal de Physique IV Proceedings, 1997, 07 (C1), pp.C1-479-C1-480. 10.1051/jp4:19971194 . jpa-00254844

\section{HAL Id: jpa-00254844 https://hal.science/jpa-00254844}

Submitted on 1 Jan 1997

HAL is a multi-disciplinary open access archive for the deposit and dissemination of scientific research documents, whether they are published or not. The documents may come from teaching and research institutions in France or abroad, or from public or private research centers.
L'archive ouverte pluridisciplinaire HAL, est destinée au dépôt et à la diffusion de documents scientifiques de niveau recherche, publiés ou non, émanant des établissements d'enseignement et de recherche français ou étrangers, des laboratoires publics ou privés. 


\title{
Effect of Magnetic and Material Structure on Epitaxial Garnet Coercivity
}

\author{
G. Vértesy
}

Research Institute for Materials Science, Hungarian Academy of Sciences, 1525 Budapest, P.O.B. 49, Hungary

\begin{abstract}
The stress dependent magnetic parameters of epitaxial garnet films were measured. Lattice distortion was found to have a significant effect on the uniaxial anisotropy constant and on the domain wall parameters. Although coercive properties are also expected to be sensitive to mechanical stress, this effect was not revealed because of the different individual properties of the samples. A method is suggested for determining the stress dependence of coercivity, measured on the same sample. Present results show the primary effect of material structure on the domain wall coercive field. The effect of modifying magnetic parameters is weaker, though it also leads to a change in coercivity.
\end{abstract}

Epitaxial magnetic garnet films play an important role in the study of basic magnetization processes. The stress dependent magnetic parameters of epitaxial garnet films were previously measured as a function of lattice mismatch in a series of samples [1]. Lattice distortion - due to the different sizes of the substituting ions in the crystal lattice - was found to have a significant effect on the uniaxial anisotropy constant and on the domain wall parameters. Although cocrcivity - a very important parameter in any application of magnetic materials - was also expected to be sensitive to mechanical stress through the domain wall parameters, this effect was not revealed. A possible explanation is that the measurements were performed on a series of samples with different individual properties (originating in the slightly different growth conditions), which blurred the effect.

The aim of this work is to find a direct, empirical correlation between the mechanical distortion of the lattice - due to lattice mismatch - and the coercive properties of the material.

For the measurements epitaxial garnet films with the nominal composition ( $\mathrm{YSmCa})_{3}(\mathrm{FeGe})_{5} \mathrm{O}_{12}$ were used. The films were grown by liquid phase epitaxy, (LPE) on (111) oriented $\mathrm{Gd}_{3} \mathrm{Ga}_{5} \mathrm{O}_{12}$ (GGG) substrates [2]. The thickness of the films, $h$, was $5 \pm 0.5 \mu \mathrm{m}$; the saturation magnetic polarisation, $J_{S}\left(=\mu_{0} M_{s}\right)$, was $20 \pm 2 \mathrm{mT}$. The lattice mismatch, $\Delta$ a, was measured by X-ray diffraction [3], with an accuracy of $3 \times 10^{-5} \mathrm{~nm}$; anisotropy, $\mathrm{K}_{\mathrm{U}}$, was measured by a magnetooptical method [4], with an accuracy of $15 \mathrm{~J} / \mathrm{m}^{3} . \mathrm{H}_{\mathrm{cW}}$, the domain wall coercive field of the samples was measured by low frequency domain wall oscillation [5], with an accuracy of $4 \mathrm{~A} / \mathrm{m}$.

$\mathrm{H}_{\mathrm{cW}}$ and $\mathrm{K}_{\mathrm{u}}$ were measured on a series of samples, as a function of $\Delta \mathrm{a} ; \mathrm{K}_{\mathrm{u}}$ increases linearly with increasing $\Delta \mathrm{a}$. A knowledge of the exchange constant, $A$ and of $K_{u}$ enables us to calculate the domain wall energy density $\gamma_{w}$ and the thickness of the domain wall $\delta_{\mathrm{W}}$, based on the expressions $\gamma_{\mathrm{W}}=4\left(\mathrm{AK}_{\mathrm{u}}\right)^{1 / 2}$ and $\delta_{\mathrm{W}}=\pi\left(\mathrm{A} / \mathrm{K}_{\mathrm{U}}\right)^{1 / 2}$. Taking the values of $\mathrm{K}_{\mathrm{U}}$ from the measurement, as a function of $\Delta \mathrm{a}$, and supposing that $\mathrm{A}$ is not a function of the stresses, the dependence of domain wall energy and domain wall width on the lattice mismatch is obtained. The value of $A$ is taken from the literature [6]. These correlations are shown in Fig. 1. It is seen that the domain wall energy definitely increases, whereas domain wall width decreases with increasing lattice mismatch.

The parameters of the domain walls are very closely correlated with the coercive properties of the samples. Consequently, an increase of coercivity should have been found with increasing lattice mismatch. But measurements did not reveal any correlation between coercive field and $\Delta \mathrm{a}$. The scatter of $\mathrm{H}_{\mathrm{cw}}$ values is too high to observe any dependence. The cause of the above mentioned discrepancy is the very strong influence of the growth conditions on the structural properties of the samples. This effect is significantly stronger than the modification of magnetic parameters because of the mechanical stress, in view of which the weaker dependence of the coercivity on the lattice mismatch is not seen.

To reveal the direct correlation between coercive field and mechanical stress, the magnetic parameters should be measured in the same sample, having different lattice distortion. Relaxation of the mechanical stress, without modifying the crystal structure and other magnetic parameters of the film, was performed by thinning the substrate from the rear. 


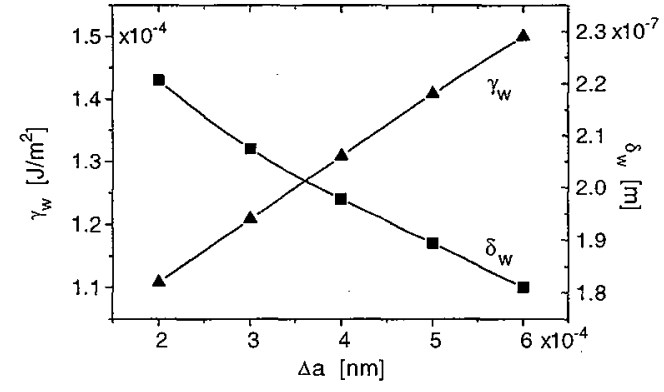

Figure 1: Domain wall energy, $\gamma_{w}$, and domain wall density, $\delta_{\mathrm{w}}$, as a function of the lattice mismatch, $\Delta \mathrm{a}$

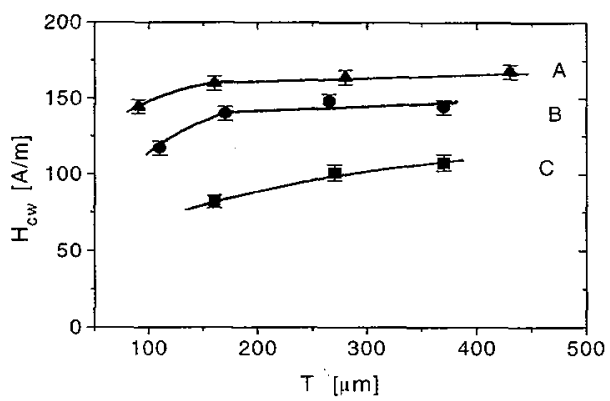

Figure 2: Coercive field. $\mathrm{H}_{\mathrm{cw}}$, of samples A-C as a function of substrate thickness $T$

This procedure was carried out on three different garnet films (samples $A-C$ ). The substrate was removed in three successive steps, after each of which all magnetic parameters were remeasured. Figs. 2 and 3 show the dependence of $H_{c w}$ and $\mathrm{K}_{\mathrm{U}}$ on the substrate thickness. The previously found $\mathrm{K}_{\mathrm{u}}(\Delta \mathrm{a})$ dependence and the results shown in Figs. 2 and 3 make it possible to obtain the wanted $\mathrm{H}_{\mathrm{cw}}(\Delta \mathrm{a})$ correlation for the three thinned samples (see Fig. 4 ).

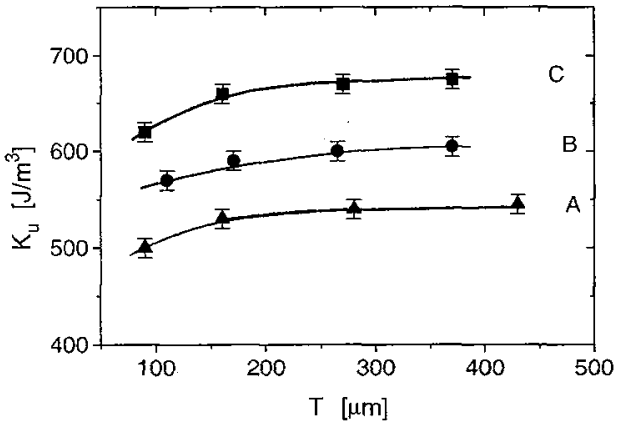

Figure 3: Uniaxial anisotropy constant, $\mathrm{K}_{\mathrm{u}}$ of samples A-C, as a function of substrate thickness $T$

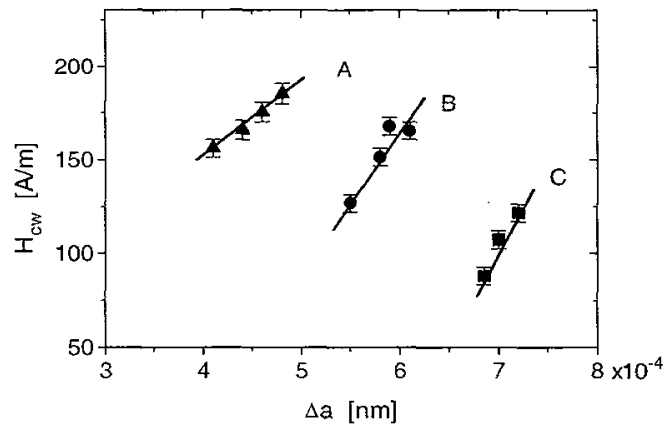

Figure 4: Coercive field, $\mathrm{H}_{\mathrm{cW}}$, of samples A-C as a function of lattice mismatch, $\Delta a$

In this way a quantitative, empirical correlation was found between the lattice mismatch and the domain wall coercive field, $\mathrm{H}_{\mathrm{cW}}$. As expected, $\mathrm{H}_{\mathrm{cw}}$ increases with increasing lattice mismatch. The slope is nearly the same for all the investigated samples. The results show the primary effect of the material structure on the domain wall coercive field. The effect of modifying the magnetic parameters is weaker, though it also leads to a change in the coercivity; however, this is measurable only by appropriate processing on the same sample.

The measurements support the idea that coercivity is the parameter which is most dependent on the individual properties of different, although similarly grown samples. Such measurements also provide a useful means of showing how the influence of the two different sources of coercivity (material imperfections and domain wall parameters) can be distinguished.

\section{Acknowledgements}

The author is indebted to Drs. B. Keszei and $\mathbf{J}$. Sasvári for growing the film and measuring lattice mismatch. Financial support from the PECO Project (Contract No. CIPA-CT93-0239) is appreciated.

\section{References}

[1] G. Vértesy, "Magnetoelastic Effects and Applications, Elsevier Studies in Applied Electromagnetics in Materials, 4", Ed.

L. Lanotte, Elsevier Science Amsterdam 1993, pp. 57-62.

[2] E.A.Giess, J.Kuptsis and E.A.D.White, J.Cryst.Growth 16 (1972) 36.

[3] W.L. Bond, Acta Cryst. 13 (1960) 814.

[4] R.D.Enoch and M.E.Jones, J.Phys.E: Sci. Instrum. 8 (1975) 336.

[5] J.A.Seitchik, G.K.Goldberg and W.D.Doyle, J.Appl.Phys. 42 (1972) 1272.

[6] D.R.Krahn, P.E.Wigen and S.L.Blank, J.Appl.Phys. 50 (1978) 2189. 